\title{
Change Detection of Vegetation Cover by NDVI Technique on Catchment Area of the Panchet Hill Dam, India
}

\author{
Sumanta Bid \\ Research Scholar, Junior Research Fellow (UGC), Department of Geography, \\ The University of Burdwan, Golapbag, Barddhaman, West Bengal, India
}

\begin{abstract}
Exhaustion of green cover has been started from the very beginning of the human civilization over space. Declining trend of natural forest owing to development projects emerges as problematic issue on environment. Dam construction by impeding of natural flow of river is a fact of depletion of green plants. It affects the vegetation on both upper and lower catchment area. This disturbance can be analyzed by different methods of Vegetation Index (VI) on the basis of Remote Sensing (RS) and Geographical Information System (GIS) techniques. Normalized Difference Vegetation Index (NDVI) is one of the most usable techniques for detection of vegetation cover. It is a numerical indicator that uses the visible and near-infrared bands of the electromagnetic spectrum. The NDVI index is also important to measure the periodical change of vegetation coverage and is related to Photosynthetically Active Radiation (PAR).
\end{abstract}

The Panchet Hill dam situated in the margin of the states of West Bengal and Jharkhand was constructed in 1959 by impeding of the Damodar River which affects the surrounding vegetation in the catchment area. Main objective of this paper is to identify the change of vegetation pattern and abolition of green coverage of the area through NDVI technique.

Keywords: NDVI, Depletion, Green Cover, GIS, Dam, Catchment, PAR

\section{INTRODUCTION}

Growth of civilization is engulfing the natural courses of rivers through damming them for their own needs. Currently there are about 45,000 dam higher than 15 meters throughout the world. While some are more than 2,000 year old, about $73 \%$ have been built in the last 50 years (Dwivedi et al. 2010). The first known dam was built in 2900 BC across Nile River to protect the city of Memphis from flooding. The tallest dam (305 meter) of the world is situated in China on Yalong Jiang River and in India is Tehri Dam (261meter) on the Bhagirathi River near Tehri in Uttarakhand. Hirakund dam is the longest dam in India about $26 \mathrm{~km}$ in length, built across the Mahanadi River in the state of Orissa (Dwivedi et al., 2010). The Panchet Hill dam is an earthen dam with concrete spillway. It has a storage capacity of 170.37 million $\mathrm{m}^{3}$ to dead storage and $1497.54 \mathrm{~m}^{3} / \mathrm{s}$ to top of gates (www.dvc.gov.in). Depletion of green cover is one of the most significant effects of the Panchet Hill dam in the catchment area.

The normalized difference vegetation index (NDVI) is developed for estimating vegetation cover from the reflective bands of satellite data (Sahebjalal and Dashtekian, 2013). NDVI is a widely used technique to detect land use land cover change, especially change of vegetation area and its pattern. Due to increase of both spatial (from $\mathrm{km}$ to $\mathrm{cm}$ ) and spectral resolution (from wide band range to narrow band) of remote sensing data, it is possible to work in micro level. Satellite images are required to prepare NDVI by the GIS software. It is an indicator of vegetation health. Forest abolition is measured through the NDVI technique. It is also a powerful tool for the collection of data about vegetation from the satellite images. An important step in the utilization of satellite data to monitor change is the ability to compare images from different dates, for different plots on different scenes (Coops et al., 2008).

Main problem of this research work is environment related. Elimination of trees for the construction of Panchet Hill dam damages land and aquatic ecosystem both in upper and lower catchment area. The main aims and objectives of this work is to identify the changing pattern of riparian vegetation including related factors and the decreasing trend of green plants coverage in a temporal scale of view on the catchment area of the dam using NDVI technique based on Remote Sensing(RS) and Geographical Information System (GIS). 


\section{OVERVIEW OF NDVI}

Normalized Difference Vegetation Index (NDVI) is an index of plant greenness or photosynthetic activity. It is a commonly used and easily calculated satellite image-based proxy for vegetation productivity (Kunkel, 2011 and Scanlon, 2002). The NDVI is a simple numerical indicator (Demirel et al., 2010; Ricotta et al., 1999; Zhang et al., 2009) which is related to Photosynthetically Active Radiation (PAR) and basically measures the capability of leaves (Malo et al., 1990) and gives a measure of the vegetative cover on the land surface over wide areas. This index shows positive correlation with photosynthetic activity, vegetation cover, biomass, and Leaf Area Index (LAI) (Schmidt et al., 2000). The NDVI algorithm is computed by subtracts the red reflectance values from the near-infrared and divides it by the sum of near-infrared and red bands. The function used such follow (Tucker, 1979)

\section{NDVI $=($ NIR-RED $) /($ NIR+RED $)$}

(Whereas NIR represents the spectral reflectance in near infrared band while RED represents red band).

NDVI values are ranging from -1 to 1 . Very low value of NDVI corresponds to barren areas of rock, sand, snow, cloud etc. Moderate values represent shrub and grassland while high value indicates temperate and tropical rainforests. Bare soil is represented with NDVI values which are closest to 0 and water bodies are represented with negative NDVI values (Karaburun, 2010; Chouhan and Rao, 2011; Ramachandra and Kumar, 2004; Xie et al., 2010). The objects indicated by different NDVI values are given in the table 1 .

Table1. NDVI range and concerned objects

\begin{tabular}{|l|l|}
\hline Range of NDVI Value & Name of the Objects \\
\hline-1 & Water Body \\
\hline 0 & Bare Soil, Rock, Sand and Snow, Cloud \\
\hline $0.2-0.3$ & Shrub and Grassland \\
\hline $0.3-0.5$ & Sparse and Unhealthy Forest \\
\hline$>0.5$ & Dense and Healthy Forest \\
\hline
\end{tabular}

Source: $w w w . r e s e a r c h g a t e . n e t$

The NDVI technique is easy to implement and simple to interpret, but it has many flaws. Satellitebased NDVI are influenced by a number of non-vegetation factors: atmospheric conditions (e.g. clouds and atmospheric path-specific variables, aerosols, water vapor), satellite geometry and calibration (view and solar angles), as well as soil backgrounds and crop canopy (Holben, 1986; Soufflet et al., 1991; Justice et al., 1991). Similarly cloud shadows affect NDVI values and lead to misinterpret the result

\section{STUDY AREA}

Catchment area of the Panchet Hill dam is situated in the margin of the states of West Bengal and Jharkhand, India. Latitudinal and longitudinal extension of the area is $86^{\circ} 29^{\prime} \mathrm{E}$ to $86^{\circ} 46^{\prime} \mathrm{E}$ and $23^{\circ}$ $30^{\prime} \mathrm{N}$ to $23^{\circ} 46^{\prime} \mathrm{N}$. It is bounded by Puruliya district on east, Bankura district on south, Barddhaman district on north-east and Dhanbad district of Jharkhand on north and north western part. Maithon reservoir is also located on the north eastern part of the area. The whole area slopes down from west to east and south-east marked by the direction of the streams flowing through the area (Chatterjee et al.,1970). Damodar is the main river in this area. The area is characterized by dry and wet sub-humid tropical climate with the regime of south west monsoon. According to Köppen, the tract falls under 'Aw' type of climate (Spate, 1954). Temperature varies from $3.8^{\circ} \mathrm{C}$ in winter to $52^{\circ} \mathrm{C}$ in summer and annual rainfall varies between 1100 to $1500 \mathrm{~mm}$. The soil of the region is red lateritic residual type in general. Existence of hills and undulating lands are the another features of this area. The area is covered by Sal (Shorea robusta), Palas (Butea frondosa) and miscellaneous types of vegetation of tropical dry category. To the north-east of this area lies the 643.5 meters high Panchakot or Panchet Hill formed of Upper Gondwana sedimentaries. The Panchet Hill dam has been built on Damodar 5 kms above the confluence with the Barakar which is the tri-junction of Dhanbad, Barddhaman and Puruliya districts (Bhattacharya et al. 1985). Some information about Panchet dam is given below in the table 2. 
Change Detection of Vegetation Cover by NDVI Technique on Catchment Area of the Panchet Hill Dam, India

The location of the study area and surface drainage pattern are shown on the figure 1 and figure 2 respectively.

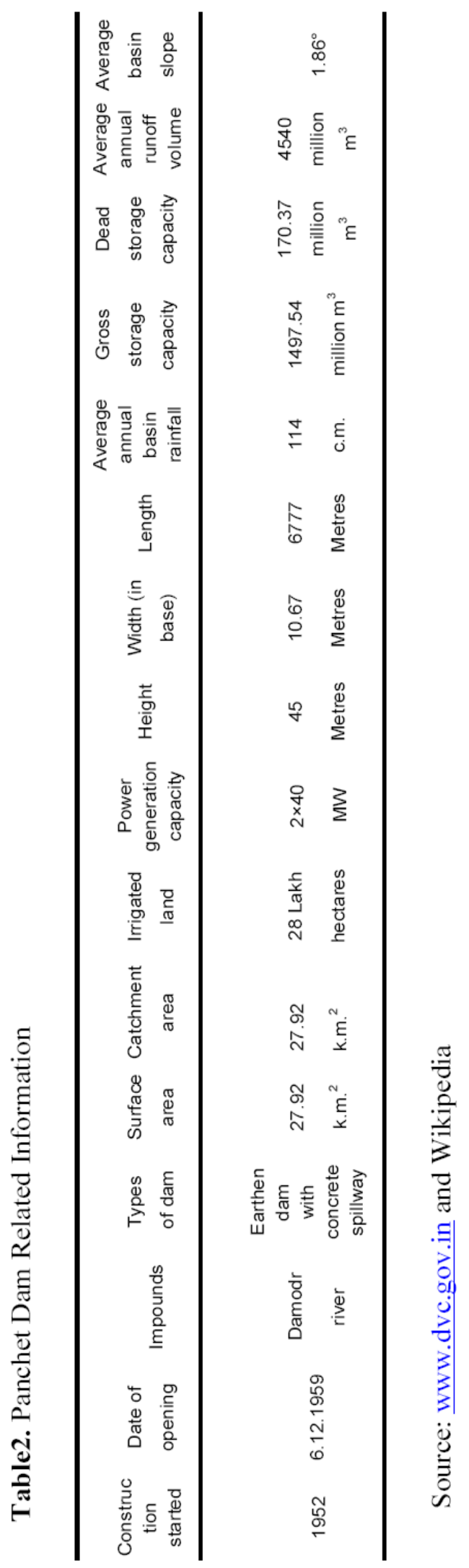




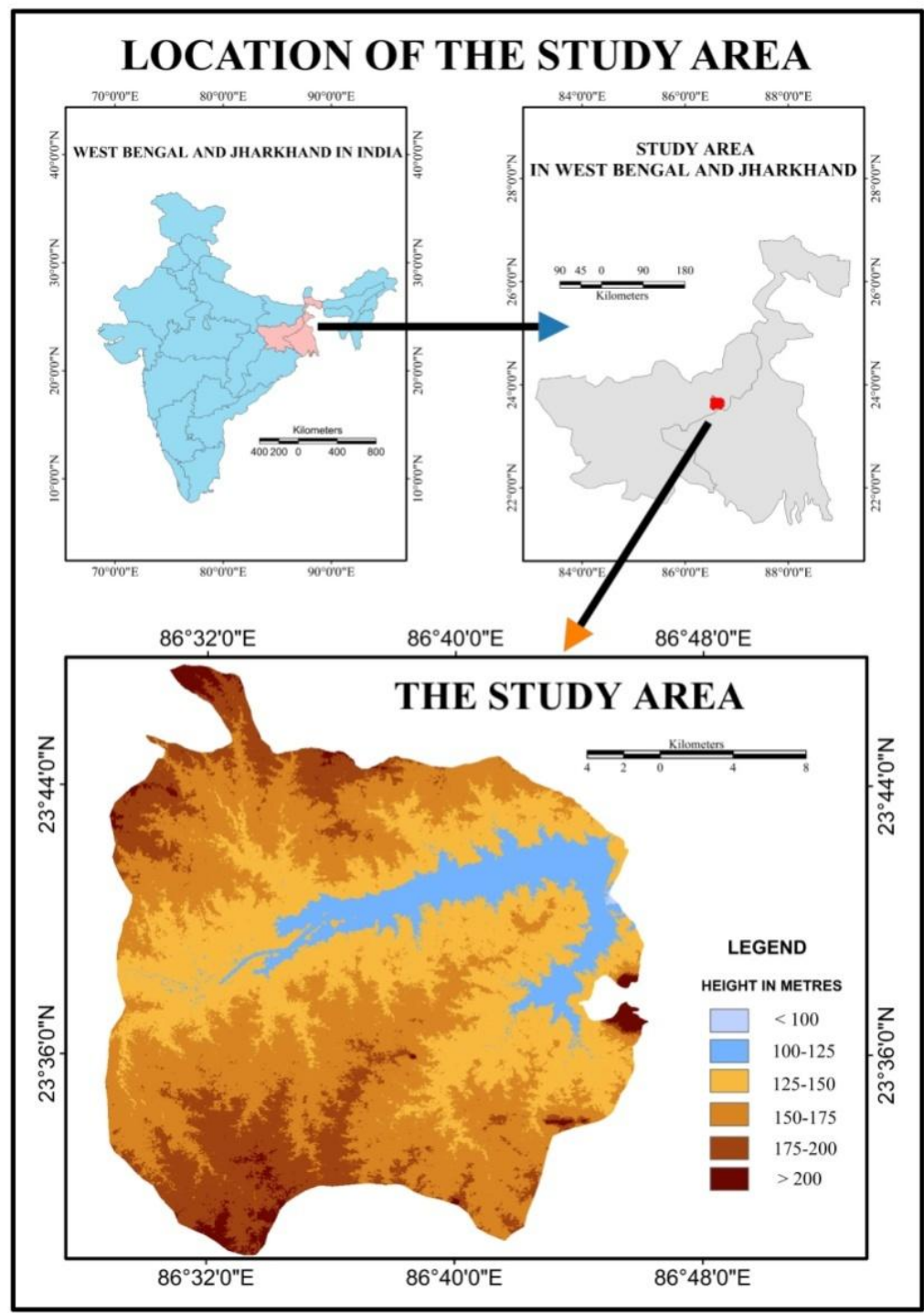

Fig1. Catchment area of the Panchet Hill Dam and its location

$86^{\circ} 24^{\prime} 0^{\prime \prime}$

$8^{\circ} 32^{\prime} 0^{\prime \prime E}$

$86^{\circ} 40^{\prime} 0^{\prime \prime E}$

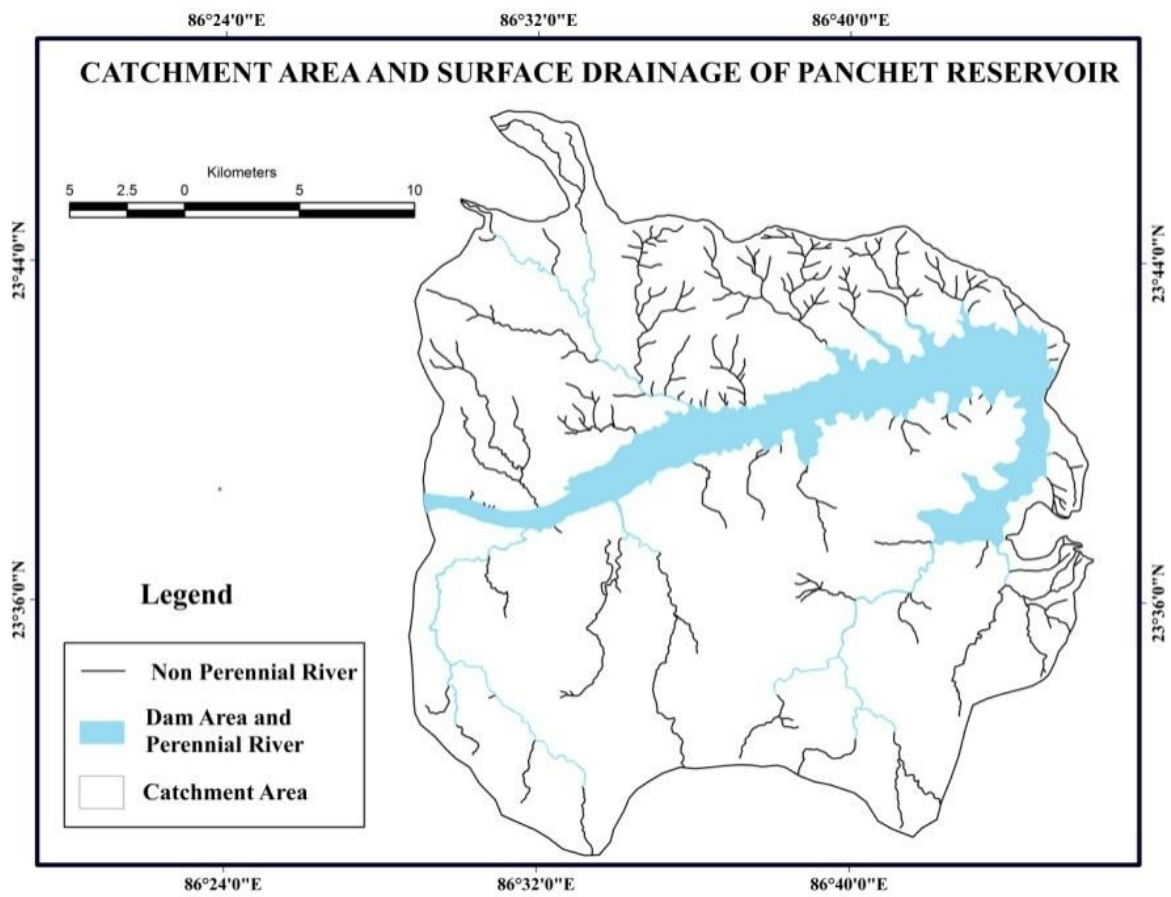

Fig2. Drainage pattern of the catchment area 

India

\section{Database and Methodology}

Latitudinal and longitudinal extension map of India, West Bengal and topographical maps of 1:250,000 (73I) and 1: 50,000 (73I/6, 73I/9, 73I/10, 73I/14) scale are collected from the cartographic lab of the Department of Geography, The University of Burdwan to show the study area. To prepare the elevation map of the area ASTER DEM data of 30 metre resolution is acquired from the link http://glcf.umd.edu/data/aster/.

Landsat data is one of the most important and accurate datasets for understanding the global land cover status which is freely provided by the United States Geological Survey (USGS). Two Landsat images downloaded from www.glovis.usgs.gov on January 5, 1990 (Image ID0101504086258_00022) and January 7, 2014 (Image ID- 0101503131929_00010) of same path and row (139/44) for the change detection of vegetation cover of the study area. The image of 1990 is Landsat 5 TM (Thematic Mapper) and 2014 is Landsat 8 OLI (Operational Land Imager). Main features of this two landsat data are shown by the table 3 below.

Table3. Characteristic Features of Satellite Data

\begin{tabular}{|ccl|rcc|cc|c|}
\hline $\begin{array}{c}\text { Date of data } \\
\text { Acquired }\end{array}$ & $\begin{array}{c}\text { Spacecraft } \\
\text { ID/Sensor }\end{array}$ & $\begin{array}{c}\text { Data } \\
\text { Type }\end{array}$ & Path Row & $\begin{array}{c}\text { Sun } \\
\text { Elevation }\end{array}$ & Projection & Datum & $\begin{array}{c}\text { UTM } \\
\text { Zone }\end{array}$ & $\begin{array}{c}\text { Spatial } \\
\text { Resolution }\end{array}$ \\
\hline $5 / 1 / 1990$ & Landsat 5 & TM & 139 & 44 & 33.49 & UTM & WGS84 & $45 N$ \\
\hline $7 / 1 / 2014$ & Landsat 8 & OLI & 139 & 44 & 38.71 & UTM & WGS84 & $45 N$ \\
\hline
\end{tabular}

Data were processed using ERDAS IMAGINE 9.2 and Arc GIS 9.3 softwares. The OLI (Operational Land Imager) data of 2014 is affected by cloud and the quality of the multispectral data is not good. It is corrected to remove atmospheric effects by the histogram equalize method and georeferenced using 30 ground control points derived from the topographical maps of 1:50,000 scale of the study area. All the data are projected to an Universal Transverse Mercator (UTM) coordinate system, Datum WGS 1984, zone 45 North using 1:50,000 topographic map of the study area. At first the 73I topographical map of 1:2,50,000 scale is georeferenced by the Arc GIS 9.3 software and creates a shape file to demarcate catchment area of the Panchet Hill dam. Standard false colour composites (FCC) are prepared from the satellite images by the band combination. The study area is extracted from the standard FCC through subset using ERDAS IMAGINE 9.2 software. Then NDVI is prepared by the same software. Separation of each and every band is essential to create NDVI from the multispectral remote sensing image. For the extraction of vegetation features, NDVI method is used at four different threshold values like 0.2, $0.3,0.4$ and 0.6 through the observation of maximum and minimum NDVI value. The final layout map of three different categories of NDVI values is created by manual method using Arc GIS 9.3 software. Finally, in order to investigate NDVI values, it is categorized into three different classes like areas with low (0.2-0.3), medium (0.3-0.4) and high $(>0.4)$ vegetation density on the basis of NDVI ranges of both 1990 and 2014 images. 0.2-0.3 NDVI value represents shrub and grassland, 0.3-0.4 indicates sparse and unhealthy forest whereas >0.4 NDVI value represents healthy and dense vegetation. Here, I use remote-sensing techniques to inspect the forest loss over the last 24 years.

\section{RESULT AND DISCUSSION}

The range of NDVI values in 1990 image from -1 to 0.56 and in 2014 image from -0.58 to 0.52 . High NDVI value indicates the high vegetation density while lower NDVI value shows the low density of vegetation. The change of vegetation pattern is shown in the table 4 and figure 3 . The area covered by vegetation was $1729.41 \mathrm{~km}^{2}$ in 1990 and $516.55 \mathrm{~km}^{2}$ in 2014 which indicates removal of $1212.86 \mathrm{~km}^{2}$ vegetation cover within a span of 24 years. In 1990 low density vegetation cover was $1539.61 \mathrm{~km}^{2}$ and it has $89.02 \%$ share of the total vegetation of the area. In 2014 this type of vegetation rapidly decreased more than 3 times and present coverage area is $449.24 \mathrm{~km}^{2}$ which means $1090.37 \mathrm{~km}^{2}$ vegetation covered area is totally abolished within 24 years at the rate of $45.43 \mathrm{~km}^{2}$ per year. The medium density vegetation covered area was $169.23 \mathrm{~km}^{2}$ in 1990 and it is decreased to $48.54 \mathrm{~km}^{2}$ in 2014 which shows more than 3 times reduction from the earlier time. Thus there is $71.37 \%$ negative change at the rate of $5.02 \mathrm{~km}^{2}$ per year. Total removal of high density vegetation is $1.80 \mathrm{~km}^{2}$ from the year $1990\left(20.57 \mathrm{~km}^{2}\right)$ to $2014\left(18.77 \mathrm{~km}^{2}\right)$ with the changing rate of $0.08 \mathrm{~km}^{2}$ per year.

Main vegetation type belongs to the NDVI value 0.2-0.3 are mixed trees with herbs and shrubs including various meditional plants like Kalmegh (Andrographis paniculata), Sarpagandha 


\section{Sumanta Bid}

(Rauvolfia serpentina) etc., Amloki (Phyllanthus emblica), Haritoki (Terminalia chebula), Bahera (Terminalia bellirica), Satamul (Asparagus racemosus), Kurchi (Holarrhena antidysenterica), Gumhar (Gmelina arborea) etc. are the trees under the NDVI range 0.3-0.4 and Sal (Shorea robusta), Polash (Butea frondosa), Neem (Azadiracta indica), are the dense vegetation belong in the >0.4 class of the NDVI range.

From the above analysis it is clear that all types of vegetation are affected by the Panchet dam. In terms of total vegetation area the maximum change is on low density vegetation category but the change of medium density vegetation cover is maximum in the case of percentage value. The high density vegetation is relatively less affected. This change of vegetation is shown in the table 4 and figure 3 . Figure 4 and figure 5 are also shown the changing pattern of vegetation in the area.

Table4. Change of Vegetation Cover from 1990 to 2014

\begin{tabular}{|c|c|c|c|c|c|c|c|c|}
\hline \multirow{2}{*}{$\begin{array}{c}\text { NDVI Density } \\
\text { Classe } \\
\text { (Vegetation Cover) }\end{array}$} & \multicolumn{2}{|c|}{$\begin{array}{c}1990 \text { NDVI } \\
\text { Classes Area }\end{array}$} & \multicolumn{2}{|c|}{$\begin{array}{l}2014 \text { NDVI } \\
\text { Classes Area }\end{array}$} & \multicolumn{2}{|c|}{$\begin{array}{c}\text { Change Between } \\
1990 \text { and } 2014\end{array}$} & \multicolumn{2}{|c|}{$\begin{array}{l}\text { Average Rate } \\
\text { of Change }\end{array}$} \\
\hline & $\mathrm{Km}^{2}$ & $\%$ & $\mathrm{Km}^{2}$ & $\%$ & $\mathrm{~km}^{2}$ & $\%$ & $\mathrm{Km}^{2} / \mathrm{Year}$ & $\%$ \\
\hline $\operatorname{Low}(0.2-0.3)$ & 1539.61 & 89.02 & 449.24 & 86.97 & -1090.37 & -70.82 & -45.43 & -2.95 \\
\hline Medium(0.3-0.4) & 169.23 & 9.79 & 48.54 & 9.40 & -120.69 & -71.37 & -5.02 & -2.97 \\
\hline $\operatorname{High}(>0.4)$ & 20.57 & 1.19 & 18.77 & 3.63 & -1.80 & -17.64 & -0.08 & -0.74 \\
\hline Total & 1729.41 & 100.00 & 516.55 & 100.00 & -1212.86 & - & - & \\
\hline
\end{tabular}

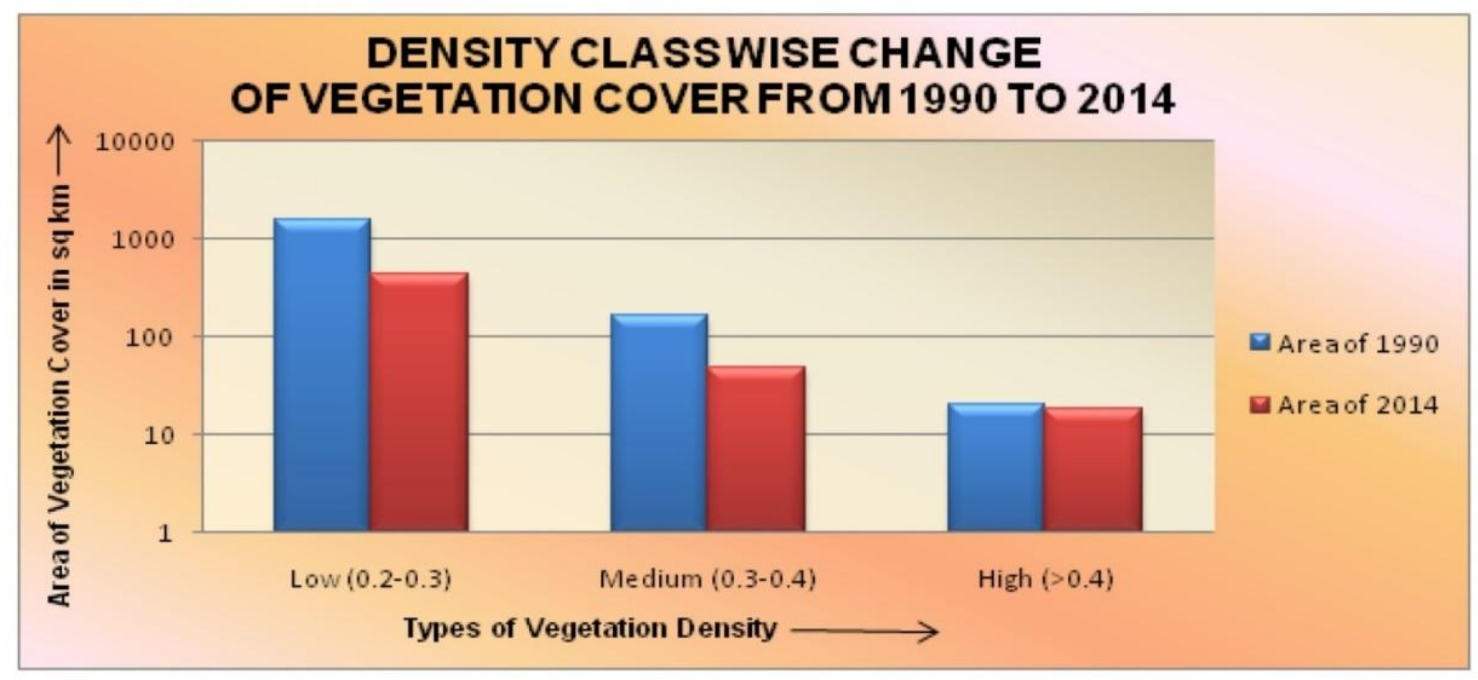

Fig3. Change of vegetation cover from 1990 to 2014

A, B of figure4 represents standard FCC and A1, B1 of figure5 represents NDVI map of the study area in 1990 and 2014 respectively.

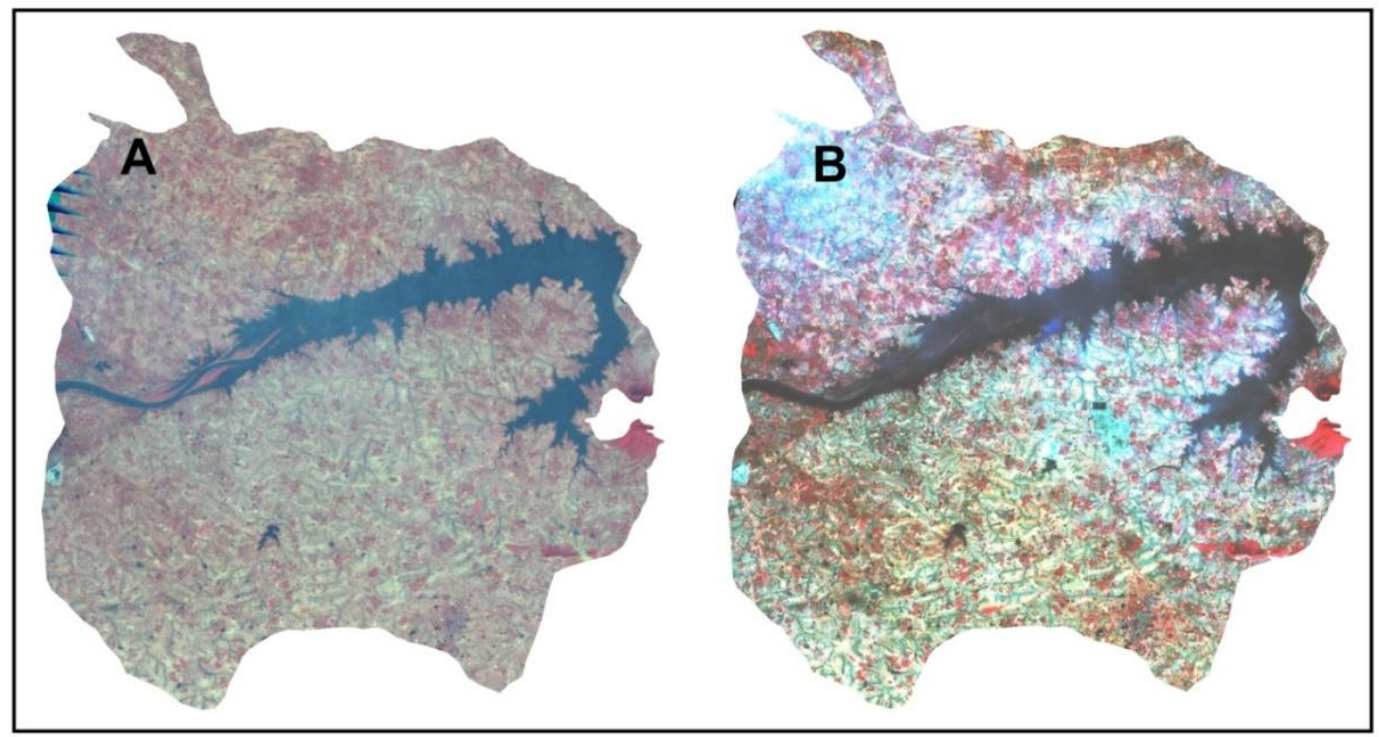

Fig4. Standard FCC of the study area in 1991 (A) and 2014 (B) 


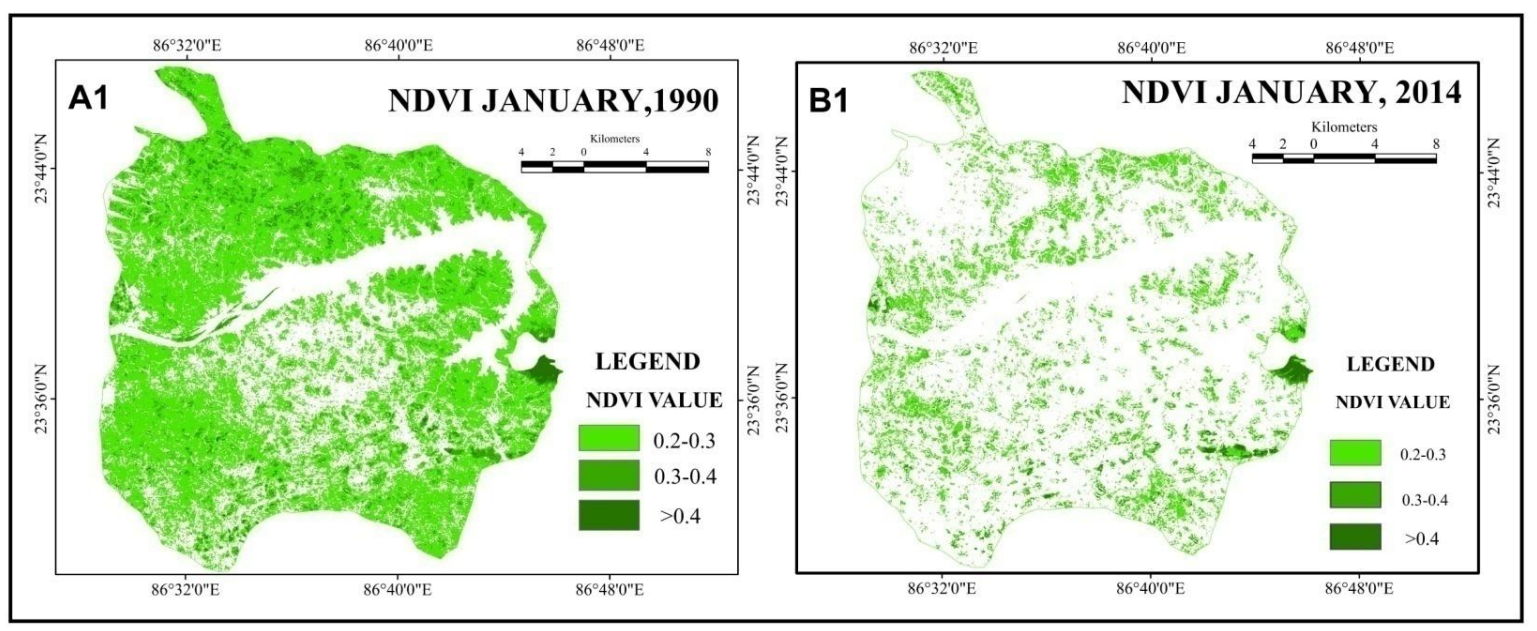

Fig5. NDVI map of the study area in 1990 (A1) and 2014 (B1)

Dam on perennial rivers affects the vegetation dynamics of both upper and lower catchment area. The diversity of river system affects the riparian trees by decreasing growth rate and increasing death rate. Dam surrounding vegetation depends on the availability of water, temperature, types and fertility of soil etc. The most common tree species in the Panchet dam area is shorea robusta. Variation in the water-levels of reservoirs can have a negative impact on plants in the immediate vicinity of the reservoir. Various plants species are decomposed during the peak season due to the increase of water level of Panchet dam in the upper catchment area. This plant community is mainly shrubs and bushes. Many riparian vegetation species are grown on shallow floodplain aquifers that are recharged during regular flood events. Minimization of the flood event by the construction of dams can have significant and complex impacts on downstream riparian plant communities. With the passage of time the riparian forest type may be replaced into another type of vegetation due to scarcity caused by the impediment of river. On the other hand dense vegetation is affected by the illegal cutting of trees for the various types of constructions associated with the Panchet dam. Illegal cutting down of plants by local people is another factor which is also responsible for the degradation of vegetation.

The assumed rate of siltation of Panchet dam is 2.44 million cubic metres whereas the observed rate is 11.75 million cubic metres (The irrigation commission, 1982). The main reason of upstream encroachment of the dam is high rate of siltation which decreases the navigation. Area of submerged by the panchet dam is 15300 ha (Singh, 2002) and 21 villages have submerged though the dam is not more than 60 years old. Submerged villages of the upper catchment area are Tantloi, Banshjor, Ghatkul, Kalmegha, Rangametya, Malancha, Hatikundar, Ankbaria, Jeratanr, Sanolapur, Katral, Naynakuri, Jeratanr, Belyadanga, Bharatpur, Telkupi, Gopalchak, Kalhajpur, Simpathar, chak Mangla, Kharikabad, Paharudi, Belyak Hajra, Kharbana, Shahchura.( Report of the Irrigation Commission, 1972) These villages were covered by green vegetation and a large number of vegetation patches were submerged under the dam.

\section{ACCURACY ASSESSMENT}

An image classification is not completed unless its accuracy has been assessed. To determine the accuracy of classification, a sample of testing pixels is selected on the classified images and their class identity is compared with the reference data (ground truth). The choice of a suitable sampling scheme and the determination of an appropriate sample size for testing data play a key role in the assessment of classification accuracy (Arora and Agarwal, 2002). Overall accuracy is a standard criterion which is used to assess the accuracy of the classifications. The Overall accuracy was defined as the total number of correctly classified pixels divided by the total number of reference pixels (total number of sample points) (Rogan et al. 2002)

To assess the accuracy of the NDVI result it is compared with the high resolution Google earth images and points of field investigation. 100 reference points are taken randomly for each class and are digitized. Baghmara is a village $\left(86^{\circ} 45^{\prime} 20^{\prime \prime} \mathrm{E}, 23^{\circ} 38^{\prime} 4^{\prime \prime} \mathrm{N}\right)$ nearest to Panchet Hill dam which is selected for accuracy assessment. After the completion of both 1990 and 2014 NDVI map superimposed them and identified total 300 points (100 points for each NDVI class) and note their coordinate values where the vegetation is removed in 2014 map at the Baghmara village and its 


\section{Sumanta Bid}

surrounding area. Then identify those coordinates in high resolution Google earth image of 2015 and also observe the same points in the time of field visit (December, 2015) by the help of GPS (Geographical Positioning System). Accuracy level is calculated on the basis of reference data viz. Google image and field verification which is shown in the table 5. The level of accuracy of the NDVI results is $89 \%$. Photos of field visit are also given in the Plate1.

Table5. Overall accuracy Calculation

\begin{tabular}{|c|c|c|c|c|}
\hline $\begin{array}{c}\text { NDVI } \\
\text { classes }\end{array}$ & $\begin{array}{c}\text { No. of taken } \\
\text { sample }\end{array}$ & $\begin{array}{c}\text { No. of sample match } \\
\text { with Google earth } \\
\text { image, 2015 }\end{array}$ & $\begin{array}{c}\text { No. of sample } \\
\text { match in field }\end{array}$ & $\begin{array}{c}\text { Average } \\
\text { accuracy } \\
\text { level in } \%\end{array}$ \\
\hline $0.2-0.3$ & 100 & 80 & 90 & 85 \\
\hline $0.3-0.4$ & 100 & 85 & 91 & 88 \\
\hline$>0.4$ & 100 & 92 & 96 & 94 \\
\hline \multicolumn{4}{|r|}{ Overall accuracy level in \% } \\
\hline
\end{tabular}

Plate1. Photograph of the field survey
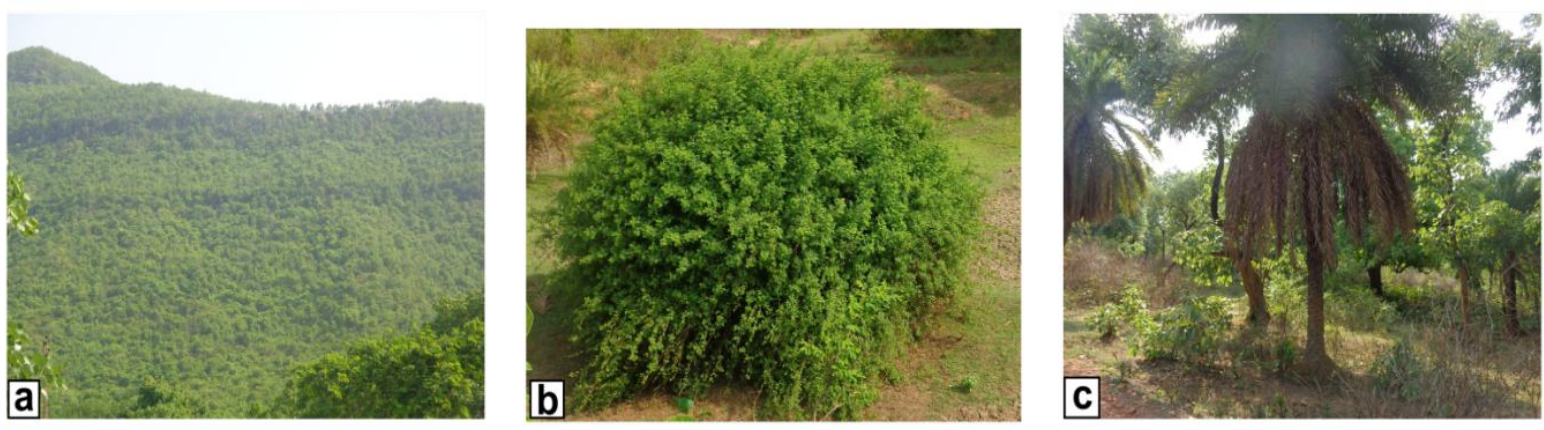

a. dense forest of Panchet hill, b. shrub and bush near to the panchet dam area, c. date palm located at the vicinity of the Panchet dam area
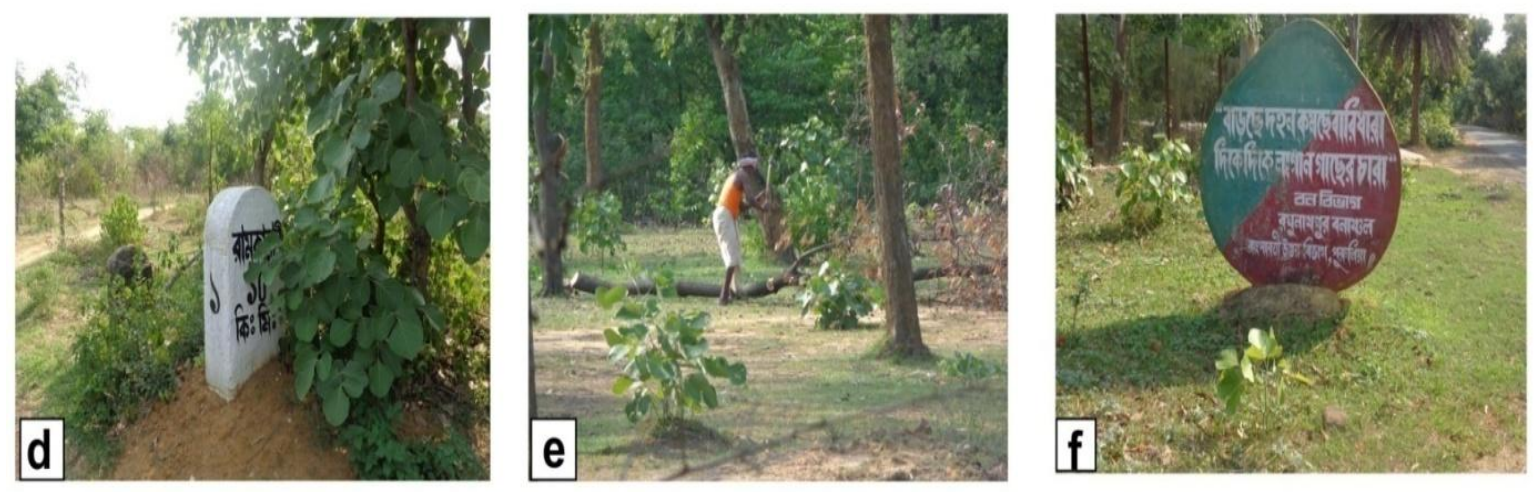

d. a cluster of Polash (Butea frondosa) near Ramkanali village, e. felling of tree by local people at Baghmara village, f. a campaign to grow consciousness about tree plantation by Raghunathpur forest division at Baghmara village.

\section{Conclusion}

Forest degradation has become a serious problem, especially in developing countries. In 2000, the total area of degraded forest in 77 countries was estimated at 800 million hectares (ha), 500 million ha of which had changed from primary to secondary vegetation (ITTO, 2002). Reduction in cover of forests at the community frontier in developing world contexts, such as that in this study, will have implications both in the global biodiversity and global warming contexts. This study has provided indicative data at the local (large) spatial scale. Such data could provide a basis for monitoring the changes in tree cover in the long-term, which is vital so as to provide threshold indicated alarms based on the rates of conversion that are subsequently established (Munyati et al., 2014).

NDVI is a significant technique to measure the evolution of land use land cover (LULC) especially change detection of vegetation pattern and its area. Very recently it is widely used in urban studies. Result of the NDVI study shows that the vegetation of medium and low density are rapidly reduced 
by the various anthropogenic causes especially construction of the Panchet Hill dam while dense vegetation is less affected because of its high altitude in the area under study. Change of total vegetation coverage is $70.13 \%$ from 1990 to 2014. So it can be said that this technique is very effective and useful for the decision making process and future planning concerned with vegetation change.

\section{REFERENCES}

[1] Arora, M. K., \& Agarwal, K., (2002). A program for sampling design for image classification accuracy assessment, Photogrammetry Journal of Finland, 18 (1), pp.33-43.

[2] Bhattacharya, B.K., et al., (1985). West Bengal District Gazetteers: Puruliya, Government of West Bengal.

[3] Chatterjee, A.B., Gupta, A., Mukhopadhyay, K.L., \& Mukhopadhyay, P.K., ed. (1970). West Bengal, Firma, Calcutta.

[4] Chouhan, R., Rao, N., (2011). Vegetation detection in multispectral remote sensing images: protective role-analysis of coastal vegetation in 2004 Indian Ocean Tsunami, Geo-Information for disaster management, Turkey.

[5] Coops, N., Bi, H., Barnett, P., \& Ryan, P., (1999). Estimating Mean and Current Annual Increments of Stand Volume in a Regrowth Eucalypt Forest Using Historical Landsat Multi Spectral Scanner Imagery, Journal of Sustainable Forestry, 9:3-4, pp 149-168, DOI: 10.1300/J091v09n03_07

[6] Demirel, H., Ozcinar, C., \& Anbarjafari, G., (2010). Satellite image contrast enhancement using discrete wavelet transform and singular value decomposition, IEEE Geosciences and remote sensing letters, 7 (2), pp. 333-337.

[7] Dwivedi, V.K., Gupta, S.K., \& Pandey, S. N., (2010). A Study of Environmental Impact Due to Construction and Operation of Dam, National Conference on Eco friendly Manufacturing for Sustainable Development, GLA University, Mathura, U.P. India, No. 31.

[8] Holben, B.N., (1986). Characteristics of maximum-value composite images from temporal AVHRR data, Int. J. Remote Sens, 7, pp. 1395-1416.

[9] International Tropical Timber Organization., (2002). ITTO guideline for the restoration, management and rehabilitation of degraded and secondary tropical forests, ITTO policy development series no. 13, Yokohama, Japan.

[10] Justice, C.O., Eck, T.F., Tanré, D., \& Holben, B.N., (1991). The effect of water vapour on the NDVI derived for the Sahelian region from NOAA AVHRR data, Int. J. Remote Sens, 12, pp.1165-1188.

[11] Karaburun, A., (2010). Estimation of $\mathrm{C}$ factor for soil erosion modeling using NDVI in Buyukcekmece watershed, Ozean journal of applied sciences, 3, pp.77-85.

[12] Kunkel, M.L., Flores, A.N., Smith. T.J., McNamara, J.P., Benner, S.G., (2011). A simplified approach for estimating soil carbon and nitrogen stocks in semi-arid complex terrain, Geoderma,165, pp.1-11.

[13] Malo, A.R., \& Nicholson, S.E., (1990). A study of Rainfall dynamics in African Sahel using Normalized Difference Vegetation Index, Journal of Arid Environment, 19, pp.1-24.

[14] Ramachandra, T.V., Kumar, U., (2004). Geographic resources decision support system for land use land cover dynamics analysis, in proceedings of the FOSS/GRASS users conferenceBangkok, Thailand, pp. 12-14.

[15] Munyati, C., \& Sinthumule, N. I., (2014). Cover Gradients and the Forest-Community Frontier: Indigenous Forests Under Communal Management at Vondo and Xanthia, South Africa, Journal of Sustainable Forestry, 33:8, pp 757-775, DOI:10.1080/10549811.2014.925809

[16] Report of the Irrigation Commission, (1972). Vol 1, pp.326-328.

[17] Ricotta, C., Avena, G., \& Palma, A.D., (1999). Mapping and monitoring net primary productivity with AVHRRNDVI time-series: statistical equivalence of cumulative vegetation indices, ISPRS journal of photogrammetry \& remote sensing, 54, pp. 325-331. 
[18] Rogan, J., Franklin, J., \& Roberts, D.A., (2002). A comparison of methods for monitoring multitemporal vegetation change using Thematic Mapper imagery, Remote Sens. Environ., 80(1), pp.143-156.

[19] Rouse, J. W., Haas, R. H., Schell, J. A., and Deering, D. W., (1973). Monitoring vegetation systems in the Great Plains with ERTS, Third ERTS Symposium, NASA SP-351I, pp.309-317.

[20] Sahebjalal, E., and Dashtekian, K., (2013) Analysis of land use-land covers changes using normalized difference vegetation index (NDVI) differencing and classification methods, African Journal of Agricultural Research, academic journal,vol8, no 37 p. 4614.

[21] Scanlon, T.M., Albertson, J., Caylor, K., and Williams, C., (2002). Determining land surface fractional cover from NDVI and rainfall time series for a savanna ecosystem., Remote Sens Environ 82, pp. 376-388.

[22] Schmidt, H., \& Karnieli, A. J., (2000), of Arid Environ, 45, pp.43-59.

[23] Singh, S., \& Banerji, P., (eds.) (2002). Large Dams in India - Environmental, Social and Economic Impacts, Indian Institute of Public Administration, New Delhi, 338.

[24] Soufflet, V., Tanré, D., Begue, A., Podaire, A., \& Deschamps, P.Y., (1991). Atmospheric effects on NOAA AVHRR data over Sahelian regions, Int. J. Remote Sens, 12, pp. 1189 -1204.

[25] Spate, O.H.K., \& Farmer, B.H., (1954). India and Pakistan - A Regional Geography, Methuen \& Co. Ltd., London.

[26] Tucker, C.J., (1979). Red and photographic infrared linear combinations for monitoring vegetation, J Remote Sens Environ, 10 (1), pp. 23-32.

[27] Xie, Y., Zhao, X., Li, L., \& Wang, H., (2010). Calculating NDVI for landsat7 etm data after atmospheric correction using 6s model: a case study in Zhangye City, Chin, In proceeding IEEE geoinformatics 18th international conference on digital object identifier, pp.1-4.

[28] Zhang, X., Hu, Y., Zhuang, D., Oi, Y., \& Ma, X., (2009). NDVI spatial pattern and its differentiation on the Mongolian Plateau, Journal of geographical sciences, 19, pp. 403-415.

\section{AUTHOR's BIOGRAPHY}

Sumanta Bid is a research scholar (UGC-JRF) in Geography, department of Geography, The University of Burdwan. His research area is DevelopmentEnvironment Conflict and research interest fields are Soil Geography, Environmental Studies and Man-Animal Conflict especially Human-Elephant Conflict (HEC) in South Bengal. 